\section{The Prevalence of Thinness and Associated Risk Factors among School Going Adolescents in Juba, South Sudan}

\section{Abstract}

Background: Adolescence is a stage of growth characterized with intense anabolism. During this stage the body requirements for all nutrients increases. Children at this stage usually have poor feeding habits with limited nutritional awareness. Adolescents are very vulnerable to malnutrition yet for many years, their health has been neglected because they were considered to be less vulnerable to disease than the young children or the elderly. Not until the past decade that their health attracted global attention. As a result this study seeks to ascertain the prevalence of underweight and possible associated factors in the school going adolescents in Juba, South Sudan.

Results: About $39.5 \%$ (25.2\% grade $1,7.6 \%$ grade 2 and $6.7 \%$ grade 3 ) of the participants were underweight with the majority $(60.5 \%)$ within normal range of BMI. Female students were half as likely to be underweight ( $O R=0.46, p$-value $=0.00$ ) compared to their male counterparts. In-take of greens ( $p$-value $=0.98)$ and meat ( $p$-value $=0.95)$ was not associated with underweight. Engagement in physical activity was not associated with underweight ( $p$-value $=0.26)$. Though not significantly associated with underweight, those that walked to school or those that used bicycles were $28 \%$ more likely to be underweight compared to those that went to school by either car or bus. Spending leisure time doing sports was not associated with being underweight ( $p$-value $=0.31)$. The number of meals in a day was not associated with underweight. Those that had physical activity at least twice were $15 \%$ more likely to be underweight compared to those that had it only once. This was however not significant ( $p$-value=0.84). The amount of pocket money received by the student was not associated with underweight.

Keywords: Underweight; BMI; Adolescents; South Sudan
Andrew $\mathrm{AK}^{1 *}$, Timothy $\mathrm{C}^{2}$ and Twinomujuni $E^{3}$

1 Department of Foods and Sugar Technology, College of Applied and Industrial Sciences, University of Juba, P.O. Box 82, Juba, South Sudan

2 Andre Foods International, P.O. Box 830 Entebbe, Uganda

3 United Nations World Food Programme, P. O. Box 7159, Kampala, Uganda

*Corresponding author:

Andrew AK

kiri_andrew@yahoo.com

Department of Foods and Sugar Technology, College of Applied and Industrial Sciences, University of Juba, P.O. Box 82, Juba, South Sudan.

Tel: +256772438219

Citation: Andrew AK, Timothy C, Twinomujuni E (2018) The Prevalence of Thinness and Associated Risk Factors among School Going Adolescents in Juba, South Sudan. J Clin Nutr Diet Vol. 4 No. 1:2

Received: February 27, 2018; Accepted: March 26, 2018; Published: April 05, 2018

\section{Introduction}

Adolescents constitute $20 \%$ of the world population and are estimated to be 1.13 billion by the year 2025 [1,2]. Adolescence is a period of rapid growth and development by which up to $45 \%$ of skeletal growth takes place and 15 to $25 \%$ of adult height is achieved [3]. In addition to the increased nutritional requirements during adolescence period, poor dietary diversity and dietary inadequacies are more likely threats among adolescents due to their erratic eating pattern and having specific psychosocial factors [4]. Malnutrition passes from generation to generation, because adolescent girls that enter pregnancy with poor nutrient store are more likely to give birth to low birth weight or intrauterine growth restricted baby that is more vulnerable to metabolic disorders later in life [5]. So, adolescence period is a unique opportunity to break a range of vicious cycles of structural problems that are passed from one generation to the next, such as poverty, gender discrimination, violence, poor health, and nutrition [4].

\section{Methods}

A cross-sectional study design was employed. The study was conducted in 5 secondary school in Juba city, South Sudan. The school included: Chinese Friendship, Juba Diocesan Model SS, Juba Girls, Juba commercial S.S, and St Daneil Comboni.

\section{Study population}

This study was conducted among adolescents aged between 13 and 18 years attending secondary school in Juba city, South Sudan. 
Sample size and sampling procedure: A simple random sampling techniques was used to pick the five schools and a Systematic sampling was used to obtain the number of children from each school. A sampling frame derived from a list of pupils aged between 13-18 years in the randomly selected schools was then used.

Data analysis: Data analysis for this study was conducted using STATA ver. 14. Standardization of BMI was done using the WHO growth standards for BMI using the STATA zanthro package. Frequency distributions, summary statistics using means and standard deviation as well as results of a logistic regression was done to establish risk factors for underweight among adolescents in Juba city. Underweight was classified based on the BMI for Age Z-score (WHO) where BMI for age Z-score of $\leq-1$ and $>-2 S D$ was categorized as grade 1, BMI for age Z-score $\leq-2$ and $>-3 S D$ classified and grade 2 and a BMI for age $\leq-3$ SD was categorized a grade 3

Ethical consideration: All participants consented to participate in the study and it was made very clear that all information will be kept confidential. All participants were given feedback and advised accordingly on the measurement taken and their BMI.

\section{Results}

\section{Characteristic of the target population}

Demographic sex ratio of the participants (Male: Female) was $1: 1$; meaning males and females participated equally. The study considered 210 students. These students were nearly equally distributed between the five schools of S.t Daniel Comboni (21.9\%), Chinese friendship (222.85\%), Juba Diocesan model SS (21.9\%), Juba Girls (16.67\%) and juba commercial SS (16.67\%) (Figure 1).

\section{Amount of pocket money}

Majority (50\%) of the student received between 16 to 30 pounds of pocket money. $22.4 \%$ received between 46 to 60 Pounds, $11.9 \%$ received over 60 pounds, $8.1 \%$ received between nothing to at most 15 pounds and the least $(7.6 \%)$ received between 31 to 45 pounds (Figure 2).

\section{Level of physical activity of respondents}

Majority (86\%) of the participants were engaged in a physical activity at least once and only $13.8 \%$ engaged in a physical activity at least two times (Figure 3).

\section{Means of transport to school}

Most (71.9\%) of the students went to school by bus, a considerable fraction (23.5\%) went to school on foot about $4.2 \%$ used motorcycles and the least proportion (0.4\%) went to school on a bicycle (Figure 4).

\section{Inclusion of green vegetables and meat in diet}

A comparatively smaller proportion (20\%) of the participants had green vegetables in their diets and a sizable proportion (48.1\%) had meat in their diets (Figure 5).

\section{Nutrition status of the participants}

The average weight of the students was $52.76 \mathrm{Kg}(\mathrm{SD}=7.99)$, the Height 1.68 meters $(S D=0.08)$ and the average $\mathrm{BMI}$ was 18.77 $(S D=2.45)$. The average Age of the students in the study was 16.6 years $(S D=1.149)$ (Table 1).

About $39.5 \%$ of the students in the study were underweight while $60.5 \%$ were within the normal range of BMI (Table 2).

About one quarter the participants $(25.2 \%)$ were grade 1 underweight and the majority (58.1\%) had normal weight. However $7.6 \%$ were grade 2 underweight and the least $6.7 \%$ were grade 3 underweight (Table 3).

\section{Summary of frequency of risk factors and their association with underweight}

Female students were half as likely to be underweight $(O R=0.46$, $\mathrm{p}$-value $=0.00$ ) compared to their male counterparts. In-take of greens ( $p$-value $=0.98)$ and meat ( $p$-value $=0.95)$ was not associated with underweight. Engagement in physical activity was not associated with underweight ( $p$-value $=0.26$ ). Though not significantly associated with underweight, those that walked to school or those that used bicycles were $28 \%$ more likely to be underweight compared to those that went to school by either car or bus. Spending leisure time doing sports was not associated

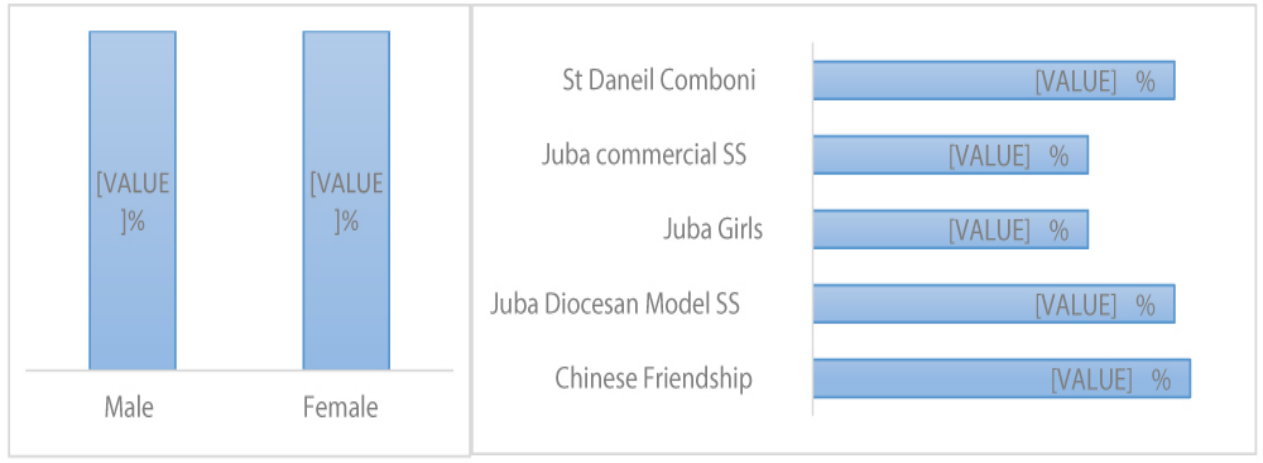

Figure 1 Gender of respondents and the distribution of students among the different target schools. 


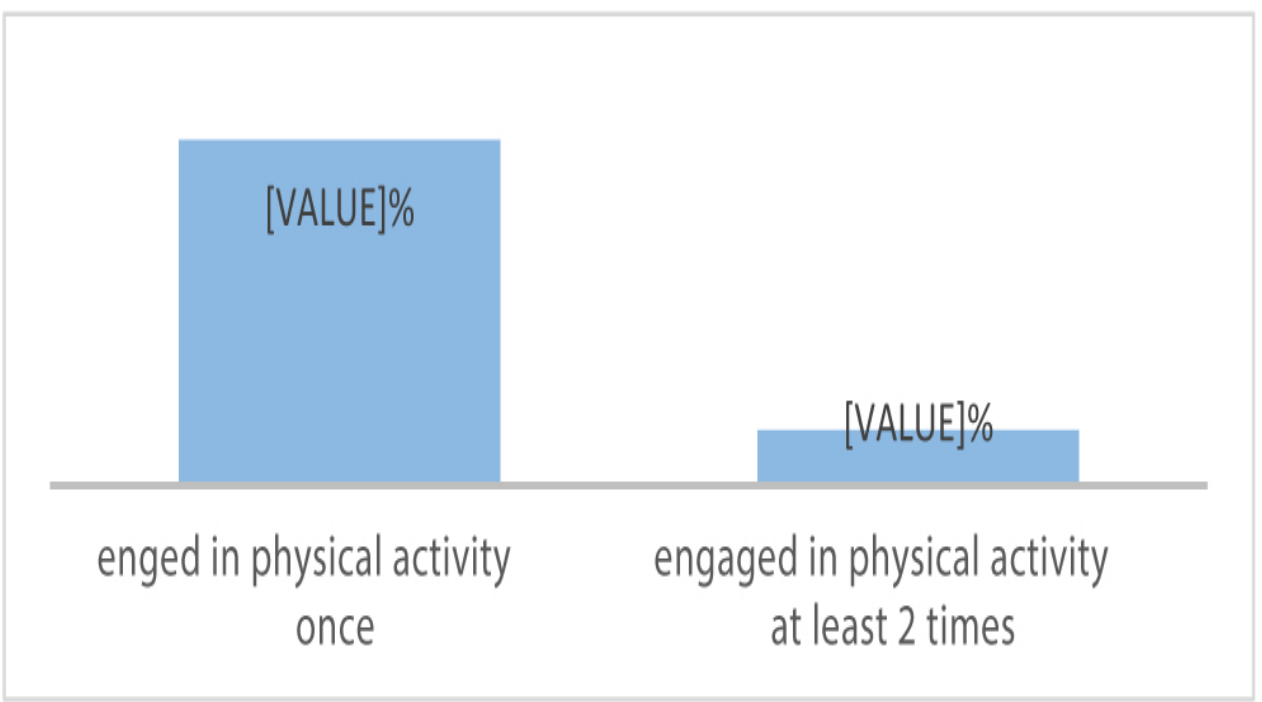

Figure 2 Proportions of students that received different amount of pocket money.

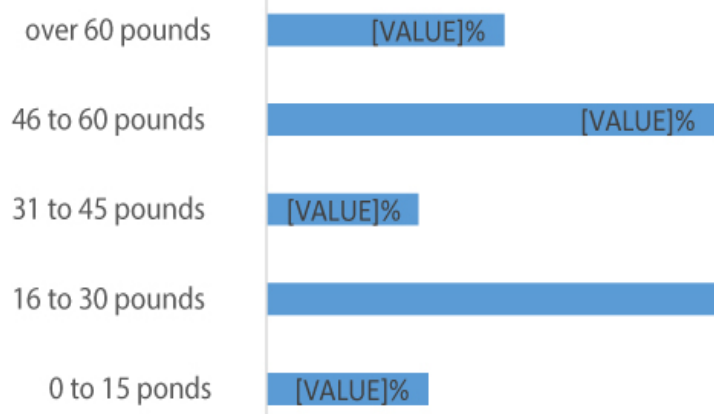

Figure 3 Proportion of students engaged in physical activity once and at least twice.

Table 1 Average age, Anthropometric measurements and BMI of respondents.

\begin{tabular}{|c|c|c|c|c|c|}
\hline & Obs & Mean & Std. Dev. & Min & Max \\
\hline Age (years) & 210 & 16.61 & 1.149 & 13 & 18 \\
\hline Weight (Kgs) & 210 & 52.76 & 7.99 & 30.2 & 87.3 \\
\hline $\begin{array}{c}\text { Height } \\
\text { (Meters) }\end{array}$ & 210 & 1.68 & 0.08 & 1.47 & 1.88 \\
\hline BMI (Kg/m2) & 210 & 18.77 & 2.45 & 13.78 & 29.51 \\
\hline
\end{tabular}

Table 2 Prevalence of underweight among respondents.

\begin{tabular}{|c|c|c|}
\hline Underweight & $\mathbf{n}$ & $\%$ \\
\hline No & 127 & 60.5 \\
\hline Yes & 83 & 39.5 \\
\hline Total & 210 & 100 \\
\hline
\end{tabular}

with being underweight ( $p$-value $=0.31$ ). The number of meals in a day was not associated with underweight. Those that had physical activity at least twice were $15 \%$ more likely to be underweight compared to those that had it only once. This was however not significant ( $p$-value $=0.84$ ). The amount of pocket money received by the student was not associated with underweight (Table 4).
Table 3 Grades of the participant's nutrition status.

\begin{tabular}{|c|c|c|}
\hline & Freq. & Percent \\
\hline Grade $\mathbf{3}$ underweight & 14 & 6.7 \\
\hline Grade $\mathbf{2}$ underweight & 16 & 7.6 \\
\hline Grade 1 underweight & 53 & 25.2 \\
\hline Normal weight & 122 & 58.1 \\
\hline Overweight & 5 & 2.4 \\
\hline Total & 210 & 100 \\
\hline
\end{tabular}

\section{Discussion}

In this study the prevalence of underweight among adolescents was $39.5 \%(25.2 \%, 7.6 \%$ and $6.7 \%$ grade 1 , grade 2 and grade 3 respectively). These findings are comparable to the findings of a study that was curried by Bovet et al. [6] in the Seychelles. Where the prevalence of thinness among adolescents was $27.7 \%, 6.7 \%$ and $1.2 \%$ grade 1,2 and 3 respectively based on the WHO cut-offs. According to Yohannes Adama Melaku et al. [7], the prevalence of thinness among adolescents students in Northern Ethiopia was $26.1 \%$ (boys $=32.4$; girls $=21.6 \%$; $p=0.017$ ), respectively with boys having higher $(\mathrm{AOR}=1.97 ; 95 \% \mathrm{Cl}: 1.19,3.25)$ odds of 
Table 4 Multivariable regression for underweight risk factors.

\begin{tabular}{|c|c|c|c|c|c|c|}
\hline & $\mathbf{n}$ & $\%$ & Unadjusted & & Adjusted & \\
\hline & & & OR & P-value & OR & P-value \\
\hline \multicolumn{7}{|c|}{ Has greens vegetables in a diet } \\
\hline no & 168 & 80 & 1 & & 1 & \\
\hline yes & 42 & 20 & 1.05 & 0.89 & 0.99 & 0.98 \\
\hline \multicolumn{7}{|l|}{ Has meat in diet } \\
\hline no & 109 & 51.9 & 1 & & 1 & \\
\hline yes & 101 & 48.1 & 0.93 & 0.78 & 1.01 & 0.95 \\
\hline \multicolumn{7}{|c|}{ Engaged in physical activity } \\
\hline no & 7 & 3.3 & 1 & & 1 & \\
\hline yes & 203 & 96.7 & 0.48 & 0.34 & 0.39 & 0.26 \\
\hline \multicolumn{7}{|c|}{ Means of transport to school } \\
\hline bus or motorcycle & 158 & 75.2 & 1 & & 1 & \\
\hline bicycle or footing & 52 & 24.8 & 1.17 & 0.64 & 1.28 & 0.49 \\
\hline \multicolumn{7}{|c|}{ Spends leisure time doing sports } \\
\hline no & 190 & 90.5 & 1 & & 1 & \\
\hline yes & 20 & 9.5 & 0.63 & 0.36 & 0.58 & 0.31 \\
\hline \multicolumn{7}{|l|}{ No. of meals each day } \\
\hline one & 52 & 24.8 & 1 & & 1 & \\
\hline two & 134 & 63.8 & 0.39 & 0.47 & 0.89 & 0.75 \\
\hline three or more & 24 & 11.4 & 1.36 & 0.53 & 2.34 & 0.17 \\
\hline \multicolumn{7}{|c|}{ No. of times engaged in physical activity } \\
\hline once & 181 & 86.2 & 1 & & 1 & \\
\hline At least 2 times & 29 & 13.8 & 1.09 & 0.83 & 1.15 & 0.84 \\
\hline \multicolumn{7}{|c|}{ Amount of pocket money } \\
\hline 0 to 15 & 17 & 8.1 & 1 & & 1 & \\
\hline 16 to 30 & 105 & 50 & 1.07 & 0.9 & 1.12 & 0.84 \\
\hline 31 to 45 & 16 & 7.6 & 0.86 & 0.83 & 0.95 & 0.95 \\
\hline 46 to 60 & 47 & 22.4 & 0.67 & 0.49 & 0.62 & 0.47 \\
\hline over 60 & 25 & 11.9 & 0.95 & 0.94 & 0.7 & 0.63 \\
\hline \multicolumn{7}{|l|}{ Sex } \\
\hline Male & 125 & 48.1 & 1 & & 1 & \\
\hline Female & 135 & 51.9 & 0.57 & 0.05 & 0.46 & 0 \\
\hline Total & 210 & 100 & & & & \\
\hline
\end{tabular}

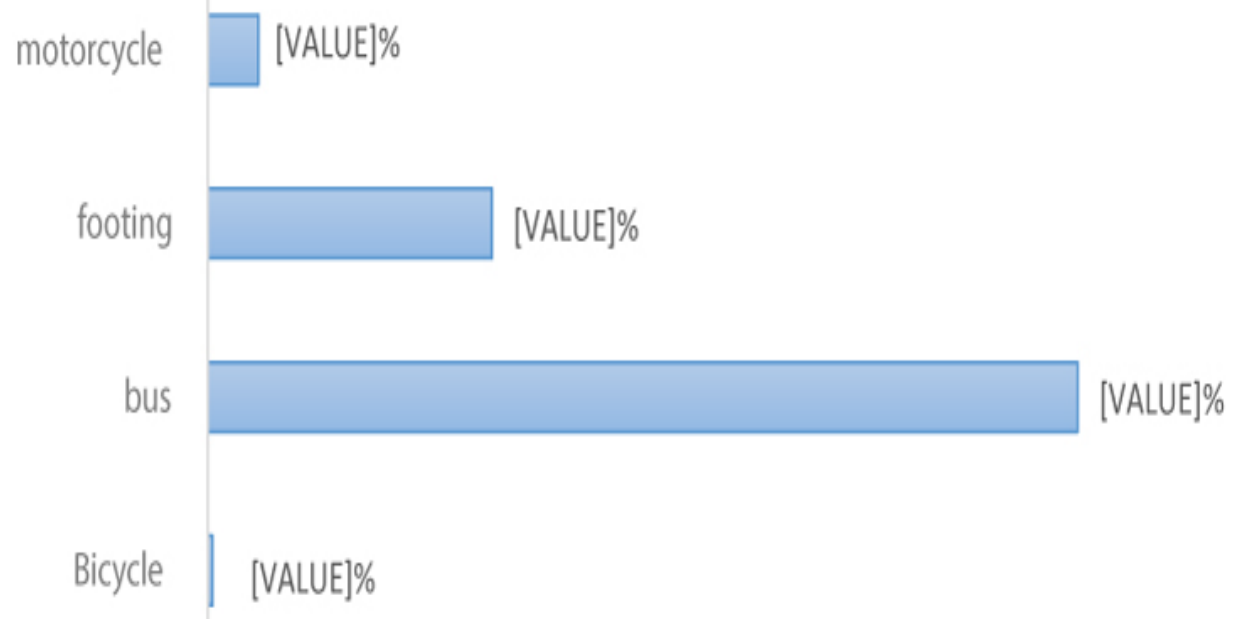

Figure 4 Proportion of students using different means of transportation to school. 


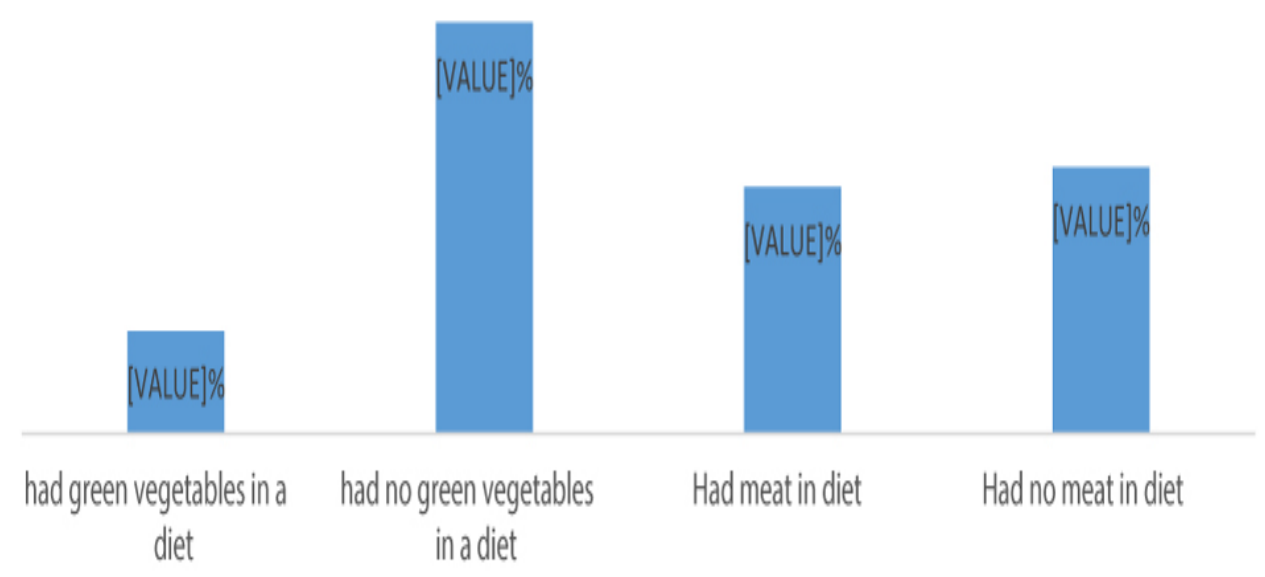

Figure 5 Presence of green vegetables and meat in diet.

being thin compared to girls which relates to the findings from the present study where female students were half as likely to be underweight $(\mathrm{OR}=0.46, \mathrm{p}$-value $=0.00)$ compared to their male counterparts.

\section{Conclusion \& Recommendations}

Addressing adolescence nutrition challenges is of great importance due to the adverse negative effects of adolescent malnutrition to future offspring processes. The study indicates the need for adolescent focused nutrition interventions with results showing the prevalence of underweight among the participants

\section{References}

1 Kalhan M, Vashisht B, Kumar V, Sharma S (2010) Nutritional status of adolescent girls of rural Haryana. Internet J Epidemiol 8.

2 Delisle H(2005) Nutrition in adolescence-issues and challenges for the health sector. Issues in adolescent health and development. Geneva, Switzerland: World Health Organization.

3 Stang J, Story M (2005) Adolescent growth and development. In: Stang J., Story M., editors. Guidelines for Adolescent Nutrition Services. Chapter 1. pp: 1-8.

4 Delisle H, Chandra-Mouli V, de Benoist B (2014) Should adolescents be specifically targeted for nutrition in developing countries: to being about 39.5\%. Meal frequency, participation in physical exercise and consumption of greens/meat were not associated with underweight but this study provides a background to generating further studies to understand other risk factors associated with adolescent malnutrition. Much as these results may not be generalizable for the whole country, considerations on geographical regional differences, out of school adolescents and other socioeconomic factors may be important to inform policy formulation around adolescent nutrition. Findings from this study can also be used to design specific public health interventions to address adolescent nutrition needs incorporating special focus areas for both boys and girls. address which problems, and how? World Health Organization/ International Nutrition Foundation for Developing Countries.

5 Guilloteau P, Zabielski R, Hammon HM, Metges CC (2009) Adverse effects of nutritional programming during prenatal and early postnatal life, some aspects of regulation and potential prevention and treatments. J Physiol Pharmacol 60: 17-35.

6 Bovet P, Kizirian N, Madeleine G, Blössner M, Chiolero A (2011) Prevalence of thinness in children and adolescents in the Seychelles: comparison of two international growth references. Nutr J 10: 65 .

7 Melaku YA, Zello GA, Gill TK, Adams RJ, Shi Z (2015) Prevalence and factors associated with stunting and thinness among adolescent students in Northern Ethiopia: a comparison to World Health Organization standards. 